\title{
Prognostic Significance of Incidental Prostate Cancer at Radical Cystoprostatectomy for Bladder Cancer
}

\author{
Georgios Gakis $^{a}$ Michael Rink ${ }^{b}$ Hans-Martin Fritsche ${ }^{d}$ Markus Graefen ${ }^{c}$ \\ Tina Schubert $^{\mathrm{a}}$ Fahmy Hassan $^{\mathrm{a}}$ Felix K. Chun $^{\mathrm{b}}$ Wolfgang Brummeisl ${ }^{\mathrm{d}}$ \\ Margit Fisch $^{b}$ Maximillian Burger ${ }^{d} \quad$ Arnulf Stenzl $^{a} \quad$ Markus Renninger $^{a}$ \\ ${ }^{\mathrm{a}}$ Department of Urology, University Hospital Tuebingen, Tuebingen, ${ }^{\mathrm{b}}$ Department of Urology and ${ }^{\mathrm{c}}$ Department \\ of Urology, Martini-Klinik, University Hospital Hamburg-Eppendorf, Hamburg-Eppendorf, and d Department of \\ Urology, University Hospital Regensburg, Regensburg, Germany
}

\section{Key Words}

Bladder cancer - Clinically significant · Incidental · Prostate cancer $\cdot$ Radical cystectomy · Overall survival · Outcome

\begin{abstract}
Objective: The aim of the study was to evaluate the impact of the clinical significance of incidental prostate cancer (PC) on overall survival (OS) after radical cystoprostatectomy (RC) for bladder cancer (BC). Methods: A total of 822 consecutive men underwent RC in 3 academic centers between 1996 and 2011. The clinical significance of incidental PC was determined according to the Epstein criteria. The Kaplan-Meier analysis with log-rank was used to investigate the impact of PC on OS and univariate and multivariate Cox regression analyses for risk factors of OS. The median follow-up was 36 months (interquartile range 10-49). Results: Of the 822 men, 117 (14.2\%) had clinically significant, 243 (29.6\%) insignificant and 462 (56.2) no PC at RC. Men with PC were at higher risk for lymphovascular invasion (LVI) of BC compared to men without PC $(p<0.001)$. The 5 -year OS for men with clinically significant, insignificant and no PC was $33.3,51.3$ and $51.5 \%$, respectively $(p=0.050)$. In the subgroup of $p N 0$ patients ( $n=601$ ), clinically significant PC was significantly as-
\end{abstract}

\section{KARGER}

E-Mail karger@karger.com

www.karger.com/uin sociated with inferior OS $(p=0.044)$ but not in multivariable analysis $(p=0.46)$. Conclusions: We did not find the clinical significance of incidental PC to be an independent predictor. However, the positive correlation between incidental PC and $\mathrm{LVI}$ of $\mathrm{BC}$ deserves further investigation.

(c) 2016 S. Karger AG, Basel

\section{Introduction}

Radical cystectomy (RC) represents the mainstay of treatment for muscle-invasive bladder cancer (BC) [1, 2]. Advanced pathological tumor and nodal stage as well as positive soft-tissue surgical margins (STSMs) are the main pathologic determinants of survival after RC [3]. Since outcomes of patients can vary considerably inter-individually [4], it is essential to individualize treatment based on patient-centered risk factors in order to selectively advocate the use of adjuvant modalities after RC.

Incidental prostate cancer (PC) is not an uncommon finding in RC specimens after BC surgery [5]. The reported rates of detection vary considerably (2-58\%), which is mainly due to different sampling techniques $[6,7]$. While
(C) 2016 S. Karger AG, Basel

0042-1138/16/0971-0042\$39.50/0 
there are reports in literature that biochemical recurrence does not significantly impact on survival after RC [8], there is evidence that supports the assumption that the presence of incidental PC represents an indicator of aggressive BC biology [6]. In light of recent studies reporting on the altered androgen sensitivity of $\mathrm{BC}$ in advanced stages $[9,10]$, the question arises whether the presence and clinical significance of incidental PC is an indicator for adverse outcomes of patients with invasive BC. In order to evaluate this hypothesis, we assembled a multi-institutional collaborative with the aim of determining the prognostic impact of incidental PC and its clinical significance on survival after RC.

\section{Patients and Methods}

This is a retrospective study representing data from 3 prospectively maintained databases of 3 German tertiary care centers. This study was conducted according to the provisions of the local ethics committee on each study site and conforms to the provisions of the Declaration of Helsinki. A common database was generated. Through regular communications, all data inconsistencies were solved prior to final analysis.

A total of 822 consecutive men treated with RC for BC between 1996 and 2011 were included. None of these patients received neoadjuvant treatment. In all centers, RC included the removal of the tumor-bearing bladder, prostate, seminal vesicles and bilateral pelvic lymph nodes. Adjuvant and palliative chemotherapy for BC was administered at the discretion of the treating physician based on the findings of histopathologic analysis and follow-up investigations.

For BC, the following clinical and pathologic parameters were assessed: age at RC, Eastern Cooperative Oncology Group (ECOG) performance status, pathologic tumor and nodal stage, STSMs, lymphovascular invasion (LVI), performance of postoperative (adjuvant and/or palliative) chemotherapy and histological subtype.

For incidental PC, the following clinical and pathologic parameters were evaluated: preoperative digital rectal examination (DRE), preoperative prostate-specific antigen (PSA) level, prostate volume, prior transurethral resection of the prostate (TURP), any prostate biopsy prior to RC, pathologic tumor and nodal stage, STSMs, lymphatic invasion, vascular invasion, Gleason-Score and tumor volume.

\section{Histologic Assessment}

The histologic assessment was performed at the center-specific pathology department by dedicated genitourinary pathologists and was based on the 1973 WHO grading system and TNM classification as approved by the AJCC [11]. The pathological macro- and microscopic evaluation of cystoprostatectomy specimens included cross-sectioning of the entire prostate at 4-5-mm intervals with immunohistochemical staining to identify the presence of bladder [12] and PC [13]. Prostate specimens were processed according to the Stanford protocol [13]. Clinically significant PC was defined as a tumor with Gleason 4 or 5 pattern, stage $\geq \mathrm{pT} 3 \mathrm{a}$, PC lymph node metastasis, positive STSM or tumor volume $>0.5 \mathrm{~cm}^{3}$ [14].

Incidental PC at Cystectomy
Positive STSMs were defined as the microscopic presence of malignant cells at the resection margins. LVI was defined as the microscopic presence of malignant cells within an endothelial cell line [15] and was separately reported for bladder and PC stage based on immunohistochemical analysis.

\section{Follow-Up}

Electronic hospital charts and physician records were reviewed to determine clinical outcomes. In all participating centers, patients generally were seen postoperatively every 3-4 months for the first year, semi-annually for the second and third years and annually thereafter. For determining overall survival (OS), clinical outcomes were measured from the date of RC to the date of death as determined by death certificates or hospital charts or the date of last follow-up when the patient had not experienced death [16]. The median follow-up was 36 months (interquartile range (IQR) 10-52).

\section{Statistical Analysis and Model Development}

For univariate analysis, the chi-square test/Fisher exact test was used for nominal data and the Student's t test for scaled data. The Kaplan-Meier plots were used to estimate OS using log-rank testing. For univariate and multivariate analyses, Cox-proportional hazard analysis was carried out to evaluate risk factors for death. $p$ values are 2 -sided and $p<0.05$ was considered significant. Statistical analysis was performed using $\mathrm{JMP}^{\circledR} 11.0$. Values are given as mean \pm SEM for all normally distributed variables or as median (range) for non-normally distributed variables.

\section{Results}

The clinical and pathologic characteristics of the 822 patients are listed in table 1 . Positive lymph nodes (all from BC) were histologically confirmed in 218 of the 822 patients $(26.5 \%$; 90 with $\mathrm{pN} 1,122$ with $\mathrm{pN} 2$ and 6 with $\mathrm{pN} 3)$. The median number of retrieved lymph nodes at RC was 18 (IQR 10-25).

Of the 822 patients, 360 (43.7\%) were diagnosed with incidental PC at RC. The rates of incidental PC between the 3 centers were $47.6,44.8$ and $35.1 \%$. Of the 360 patients with incidental PC, 243 (67.5\%) had clinically insignificant and 117 (32.5\%) clinically significant PC. The rates of clinically significant $\mathrm{PC}$ were not different across centers (center I: $14.7 \%$, center II: $14.4 \%$ and center III: $13.3 \%, \mathrm{p}=0.54)$.

Patients with significant PC were of higher age compared to patients with insignificant PC and without PC ( $p<0.001$ between the 3 groups). Compared to the group of patients with insignificant and without $\mathrm{PC}$, patients with significant PC had a positive DRE at RC $(\mathrm{p}<0.001$ between groups), a history of prostate biopsy prior to RC $(\mathrm{p}=0.015 / \mathrm{p}=0.006)$ and higher preoperative PSA levels (available data on 477 patients; $\mathrm{p}=0.002 / \mathrm{p}<0.001$ ). 
Table 1. Univariate Pearson chi-square/Fisher exact test for clinical and pathological parameters in the 822 patients with $\mathrm{BC}$ according to the presence and significance of incidental PC at RC (bold values indicate a statistically significant difference)

\begin{tabular}{|c|c|c|c|c|c|}
\hline & \multicolumn{3}{|l|}{$\mathrm{BC}$ and $\mathrm{PC}$} & \multirow{2}{*}{$\begin{array}{l}\text { BC } \\
\text { without PC }\end{array}$} & \multirow[t]{2}{*}{$\mathrm{p}$ value } \\
\hline & insignificant PC & significant $\mathrm{PC}$ & $\mathrm{p}$ value & & \\
\hline Number of patients, $\%$ & $243(29.6)$ & $117(14.2)$ & & $462(56.2)$ & \\
\hline \multicolumn{6}{|l|}{ Age at RC, years } \\
\hline Median & 68 & 71 & \multirow[t]{2}{*}{$<0.001$} & 66 & \multirow[t]{2}{*}{$<0.001$} \\
\hline IQR & $60-73$ & $67-74$ & & $57-71$ & \\
\hline \multicolumn{6}{|c|}{ ECOG performance status (at RC) } \\
\hline Mean & 0.7 & 0.8 & \multirow{3}{*}{0.58} & 0.9 & \\
\hline Median & 1 & 1 & & 1 & \\
\hline $\mathrm{IQR}$ & $0-1$ & $0-1$ & & $0-1$ & 0.20 \\
\hline \multicolumn{6}{|l|}{ Preoperative DRE } \\
\hline Positive & $76(31.3)$ & $56(47.9)$ & \multirow[t]{2}{*}{0.002} & $5(1.1)$ & \multirow[t]{2}{*}{$<0.001$} \\
\hline Negative & $167(68.7)$ & $61(52.1)$ & & 457 (98.9) & \\
\hline \multicolumn{6}{|c|}{ Preoperative PSA $(\mathrm{n}=477), \mathrm{ng} / \mathrm{ml}$} \\
\hline Mean & 3.5 & 6.7 & \multirow[t]{3}{*}{0.020} & 1.7 & \multirow{3}{*}{$<0.001$} \\
\hline Median & 2.5 & 3.2 & & 1.0 & \\
\hline IQR & $1.0-4.0$ & $1.9-5.4$ & & $0.5-2$ & \\
\hline \multicolumn{6}{|l|}{ Prostate volume, $\mathrm{ml}$} \\
\hline Mean & 22 & 25 & \multirow[t]{3}{*}{0.40} & 21 & \multirow[t]{3}{*}{0.97} \\
\hline Median & 19 & 27 & & 24 & \\
\hline $\mathrm{IQR}$ & $5-33$ & $15-33$ & & $8-34$ & \\
\hline \multicolumn{6}{|c|}{ TURP in history without malignancy } \\
\hline Yes & $3(1.2)$ & $3(2.6)$ & 0.39 & $20(4.3)$ & 0.043 \\
\hline No & $240(98.8)$ & $114(97.4)$ & & $442(95.7)$ & \\
\hline Prostate biopsy prior to & & & & & \\
\hline Yes 11 ( & $1(0.4)$ & $5(4.3)$ & 0.015 & $0(0)$ & 0.006 \\
\hline No & $242(99.6)$ & $112(95.7)$ & & $462(100)$ & \\
\hline Number of retrieved ly & & & & & \\
\hline Median & 17 & 18 & 0.49 & 18 & 0.80 \\
\hline Mean & 16.4 & 18.1 & & 17.4 & \\
\hline IQR & $7-25$ & $10-26$ & & $10-25$ & \\
\hline$B C$ & & & & & \\
\hline pT-stage (BC) & & & & & \\
\hline pTX & $1(0.4)$ & $0(0)$ & 0.19 & $1(0.2)$ & 0.42 \\
\hline pT0 & $25(10.3)$ & $11(9.4)$ & & $47(10.2)$ & \\
\hline $\mathrm{pTa}$ & $5(2.1)$ & $5(4.3)$ & & $18(3.9)$ & \\
\hline pTis & $16(6.6)$ & $12(10.3)$ & & $38(8.2)$ & \\
\hline pT1 & $32(13.2)$ & $14(12.0)$ & & $59(12.8)$ & \\
\hline pT2a & $39(16.1)$ & $12(10.3)$ & & $59(12.8)$ & \\
\hline pT2b & $14(5.8)$ & $15(12.8)$ & & $36(7.8)$ & \\
\hline pT3a & $43(17.7)$ & $13(11.1)$ & & $80(17.3)$ & \\
\hline pT3b & $33(13.6)$ & $14(12.0)$ & & $48(10.4)$ & \\
\hline pT4a & $32(13.2)$ & $18(15.4)$ & & $63(13.6)$ & \\
\hline pT4b & $3(1.2)$ & $3(2.6)$ & & $13(2.8)$ & \\
\hline$\leq \mathrm{pT} 2 \mathrm{~b}$ & $132(54.3)$ & $69(58.2)$ & 0.42 & $258(55.8)$ & 0.94 \\
\hline$\geq \mathrm{pT} 3 \mathrm{a}$ & $111(45.7)$ & $48(41.8)$ & & $204(44.2)$ & \\
\hline pN-stage (BC) & & & & & \\
\hline pNX & $0(0)$ & $0(0)$ & 0.16 & $0(0)$ & 0.88 \\
\hline pNo & $179(73.7)$ & $88(75.2)$ & & $337(72.9)$ & \\
\hline $\mathrm{pN} 1$ & $30(12.3)$ & $11(9.4)$ & & 49 (10.6) & \\
\hline $\mathrm{pN} 2$ & $34(14.0)$ & $16(13.7)$ & & $72(15.6)$ & \\
\hline $\mathrm{pN} 3$ & $0(0)$ & $2(1.7)$ & & $4(0.9)$ & \\
\hline STSM (BC) & & & & & \\
\hline $\mathrm{pRX}$ & $1(0.4)$ & $0(0)$ & 0.44 & $3(0.6)$ & 0.96 \\
\hline pR0 & $219(90.1)$ & $102(87.2)$ & & $411(89.0)$ & \\
\hline $\mathrm{pR} 1$ & $22(9.1)$ & $15(12.8)$ & & $46(10.0)$ & \\
\hline $\mathrm{pR} 2$ & $1(0.4)$ & $0(0)$ & & $2(0.4)$ & \\
\hline
\end{tabular}


Table 1. (continued)

\begin{tabular}{|c|c|c|c|c|c|}
\hline & \multicolumn{3}{|l|}{$\mathrm{BC}$ and $\mathrm{PC}$} & \multirow{2}{*}{$\begin{array}{l}\text { BC } \\
\text { without PC }\end{array}$} & \multirow[t]{2}{*}{$\mathrm{p}$ value } \\
\hline & insignificant PC & significant PC & $\mathrm{p}$ value & & \\
\hline \multicolumn{6}{|l|}{ LVI (BC) } \\
\hline LV0 & $100(41.2)$ & $55(47.0)$ & 0.99 & $237(51.3)$ & $<0.001$ \\
\hline LVI & $95(39.1)$ & $52(44.4)$ & & $107(23.2)$ & \\
\hline LVX & $48(19.8)$ & $10(5.5)$ & & $118(25.5)$ & \\
\hline \multicolumn{6}{|l|}{ Histology } \\
\hline Pure UC & $208(85.6)$ & $99(84.6)$ & 0.23 & $358(77.5)$ & 0.17 \\
\hline Pure SCC & $4(1.7)$ & $3(2.6)$ & & $8(1.7)$ & \\
\hline Pure AC & $1(0.4)$ & $0(0)$ & & $2(0.4)$ & \\
\hline $\mathrm{UC}+\mathrm{SCC}$ & $10(4.1)$ & $4(3.4)$ & & $9(2.0)$ & \\
\hline Small cell & $3(1.2)$ & $2(1.7)$ & & $1(0.2)$ & \\
\hline $\mathrm{SCC}+\mathrm{UC}$ & $0(0)$ & $3(2.6)$ & & $7(1.5)$ & \\
\hline Sarcomatoid + UC & $3(1.2)$ & $0(0)$ & & $2(0.4)$ & \\
\hline $\mathrm{UC}+$ sarcomatoid & $1(0.4)$ & $0(0)$ & & $6(1.3)$ & \\
\hline $\mathrm{UC}+\mathrm{AC}$ & $0(0)$ & $0(0)$ & & $2(0.4)$ & \\
\hline UC + small cell + sarcomatoid & $0(0)$ & $1(0.9)$ & & $0(0)$ & \\
\hline Pure sarcomatoid & $1(0.4)$ & $0(0)$ & & $0(0)$ & \\
\hline $\mathrm{UC}+\mathrm{SCC}+\mathrm{AC}$ & $0(0)$ & $0(0)$ & & $1(0.2)$ & \\
\hline Clear-cell + SCC & $0(0)$ & $0(0)$ & & $0(0)$ & \\
\hline Plasmozytoid & $2(0.8)$ & $0(0)$ & & $1(0.2)$ & \\
\hline Micropapillary & $0(0)$ & $0(0)$ & & $3(0.7)$ & \\
\hline Nested & $0(0)$ & $0(0)$ & & $1(0.2)$ & \\
\hline Lymphoepithelioma-like & $0(0)$ & $0(0)$ & & $0(0)$ & \\
\hline Unclassified/unknown & $10(4.1)$ & $5(4.3)$ & & $61(13.2)$ & \\
\hline \multicolumn{6}{|c|}{ Postoperative chemotherapy (BC) (adjuvant + palliative) } \\
\hline Received & $46(18.9)$ & $14(12.0)$ & 0.13 & $89(19.3)$ & 0.31 \\
\hline Adjuvant & $22(9.1)$ & $6(5.1)$ & & $26(56.3)$ & \\
\hline Palliative & $16(6.6)$ & $6(5.1)$ & & $51(11.0)$ & \\
\hline Adjuvant plus palliative & $8(3.3)$ & $2(1.7)$ & & $12(2.6)$ & \\
\hline Not received & $197(81.1)$ & $103(88.0)$ & & $373(80.7)$ & \\
\hline \multicolumn{6}{|l|}{$P C$} \\
\hline \multicolumn{6}{|l|}{ pT-stage (PC) } \\
\hline pT $2 a$ & $145(59.7)$ & $28(23.9)$ & $<0.001$ & & \\
\hline pT2b & $18(7.4)$ & $8(6.8)$ & & & \\
\hline pT2c & $68(28.0)$ & 49 (41.9) & & & \\
\hline pT3a & $4(1.7)$ & $21(18.0)$ & & & \\
\hline pT3b & $0(0)$ & $6(5.1)$ & & & \\
\hline pT4 & $0(0)$ & $5(4.3)$ & & & \\
\hline Not assessed & $8(3.3)$ & $0(0)$ & & & \\
\hline \multicolumn{6}{|l|}{ STSM (PC) } \\
\hline $\mathrm{pRX}$ & $2(0.8)$ & $1(0.9)$ & $<0.001$ & & \\
\hline pR0 & $229(94.2)$ & $95(1.2)$ & & & \\
\hline $\mathrm{pR} 1$ & $3(1.2)$ & $20(17.1)$ & & & \\
\hline Not assessed & $9(3.7)$ & $1(0.9)$ & & & \\
\hline \multicolumn{6}{|l|}{ Lymphatic invasion (PC) } \\
\hline LX & $4(1.7)$ & $0(0)$ & $<0.001$ & & \\
\hline L0 & $222(91.4)$ & $92(78.6)$ & & & \\
\hline $\mathrm{L} 1$ & $3(2.6)$ & $21(18.0)$ & & & \\
\hline Not assessed & $14(5.8)$ & $4(3.4)$ & & & \\
\hline \multicolumn{6}{|l|}{ Vascular invasion (PC) } \\
\hline $\mathrm{VX}$ & $5(2.1)$ & $0(0)$ & $<0.001$ & & \\
\hline V0 & $223(91.8)$ & $108(92.3)$ & & & \\
\hline $\mathrm{V} 1$ & $0(0)$ & $5(4.3)$ & & & \\
\hline Not assessed & $15(61.7)$ & $4(3.4)$ & & & \\
\hline \multicolumn{6}{|l|}{ Gleason score } \\
\hline 4 & $24(9.9)$ & $1(0.9)$ & $<0.001$ & & \\
\hline 5 & $35(14.4)$ & $2(1.7)$ & & & \\
\hline
\end{tabular}


Table 1. (continued)

\begin{tabular}{lllll}
\hline & \multicolumn{2}{l}{ BC and PC } & & $\begin{array}{l}\text { BC } \\
\text { without PC }\end{array}$ \\
\cline { 2 - 3 } & insignificant PC & significant PC & p value & \\
\hline 6 & $184(75.7)$ & $8(6.8)$ & \\
7 & $0(0)$ & $91(77.8)$ & \\
8 & $0(0)$ & $7(6.0)$ & \\
9 & $0(0)$ & $8(6.8)$ & \\
10 & $0(0)$ & $0(0)$ & \\
Tumor volume (PC), $\mathrm{mm}^{3}$ & & & \\
Mean & 6 & 11 & $<\mathbf{0 0 1}$ \\
Median & 5 & 12 & \\
IQR & $3-10$ & $6-15$ & \\
\hline
\end{tabular}

$\mathrm{AC}=$ Adenocarcinoma $\mathrm{SCC}=$ squamous cell carcinoma $\mathrm{UC}=$ urothelial carcinoma.

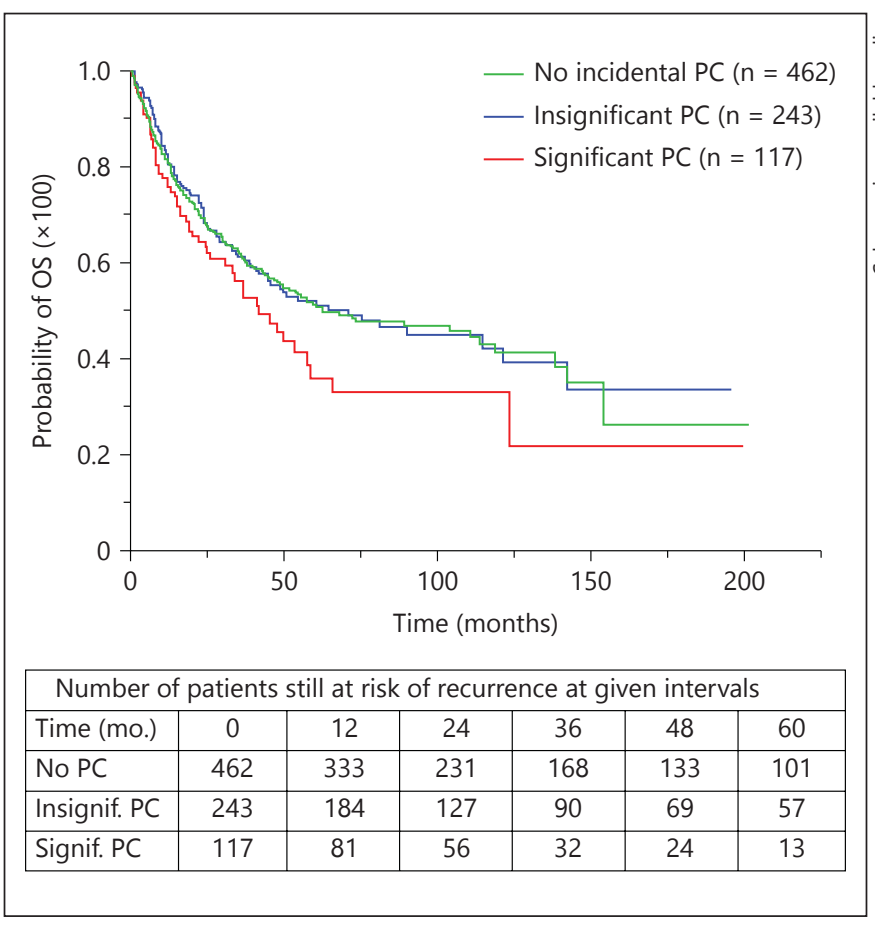

Fig. 1. Kaplan-Meier analysis for OS according to the presence and significance of incidental PC at RC for BC (insignif. = insignificant; mo. $=$ months; signif. $=$ significant; $\mathrm{p}=0.06$ for significant vs. insignificant/no incidental PC).

Patients with PC were at higher risk for LVI of BC compared to patients without PC $(\mathrm{p}<0.001)$. Conversely, patients without PC had undergone significantly more likely a TURP (for benign prostatic syndrome without evidence of malignancy) in their history $(\mathrm{p}=0.043)$.

Compared to the group of patients with insignificant PC, men with significant PC exhibited higher PC tumor stages at RC, higher PC tumor volumes, higher GleasonScores, a higher risk of positive STSMs (from PC) as well as lymphatic and vascular invasion by PC cells (all $\mathrm{p}<0.001$ ).

In the entire cohort, the 5 -year OS was $50.1 \%$. The 5 -year OS for patients with significant, insignificant and no PC was $33.3,51.3$ and $51.5 \%$, respectively ( $\mathrm{p}=0.050$; fig. 1 ).

For the entire cohort $(n=822)$ of patients, inferior OS was significantly associated with advanced age $(\mathrm{p}<$ $0.001)$, histologic advanced BC tumor stage $(\mathrm{p}<0.001)$, pathologically confirmed lymph node tumor involvement of $\mathrm{BC}$ ( $\mathrm{pN}+$ vs. $\mathrm{pN} 0$ and $\mathrm{pN} 2-3$ vs. $\mathrm{pN} 1$; both $\mathrm{p}<$ $0.001)$, positive STSMs of BC ( $p<0.001)$, LVI of BC cells $(\mathrm{p}<0.001)$, receipt of postoperative chemotherapy ( $\mathrm{p}<$ $0.001)$ and a trend toward significance for patients with significant $\mathrm{PC}$ versus insignificant/no PC $(\mathrm{p}=0.050$; table 2). Sub-analyzed for $\mathrm{pN} 0$-staged patients $(\mathrm{n}=604)$, the presence of clinically significant PC correlated with inferior OS compared to insignificant $\mathrm{PC} / \mathrm{no} \mathrm{PC}(\mathrm{p}=$ 0.044).

On multivariate analysis, adjusted for all significant variables of univariate analysis, histologically confirmed advanced BC stage $(\mathrm{p}<0.001)$, node-positive disease $(\mathrm{p}<$ $0.001)$, positive STSMs $(\mathrm{p}<0.001)$, presence of LVI $(\mathrm{p}<$ $0.001)$ and advanced age at RC ( $\mathrm{p}<0.001)$ were associated with inferior OS (table 2) whereas the clinical significance of PC $(\mathrm{p}=0.46)$ as well as the receipt of postoperative systemic chemotherapy were not $(\mathrm{p}=0.79)$.

\section{Discussion}

In the present study, we investigated the impact of incidental PC and its clinical significance on mortality in patients treated with RC for BC. Previous smaller 
Table 2. Univariate and multivariate Cox regression analyses of risk factors for death after RC in patients with BC (bold values indicate a statistically significant difference)

\begin{tabular}{|c|c|c|c|c|}
\hline \multirow[t]{2}{*}{ Parameter } & \multicolumn{2}{|l|}{ Univariable OS } & \multicolumn{2}{|l|}{ Multivariable OS } \\
\hline & RR (95\% CI) & $\mathrm{p}$ value & RR (95\% CI) & $\mathrm{p}$ value \\
\hline Significant vs. insignificant PC/no PC & $1.32(1.00-1.75)$ & 0.050 & $1.12(0.82-1.51)$ & 0.45 \\
\hline$\geq$ pT3a vs. $\leq$ pT2b (BC) & $3.74(3.00-4.68)$ & $<0.001$ & $2.52(1.93-3.29)$ & $<0.001$ \\
\hline \multicolumn{5}{|l|}{ Pathologic nodal stage } \\
\hline $\mathrm{pN}+$ vs. $\mathrm{pN} 0$ & $2.63(2.11-3.27)$ & $<0.001$ & $1.53(1.19-1.98)$ & $<0.001$ \\
\hline Positive vs. negative STSMs (BC) & $4.45(3.35-5.82)$ & $<0.001$ & $2.50(1.85-3.33)$ & $<0.001$ \\
\hline LVI vs. LV0 (BC) & $2.60(2.04-3.32)$ & $<0.001$ & $1.39(1.07-1.82)$ & $<0.001$ \\
\hline \multicolumn{5}{|l|}{ Receipt of postoperative chemotherapy } \\
\hline (no vs. yes) & $2.14(1.68-2.72)$ & $<0.001$ & $1.05(0.79-1.40)$ & 0.79 \\
\hline \multicolumn{5}{|l|}{ Age, years } \\
\hline (continuously, total range of risk) & $5.42(2.96-10.06)$ & $<0.001$ & $4.41(2.38-8.29)$ & $<0.001$ \\
\hline$>66$ vs. $\leq 66$ & $1.68(1.35-2.09)$ & $<0.001$ & & \\
\hline \multicolumn{5}{|l|}{ ECOG performance status (at RC) } \\
\hline (continuously, total range of risk) & $3.04(0.84-10.78)$ & 0.08 & - & - \\
\hline ECOG $\geq 1$ vs. 0 & $1.11(0.62-2.08)$ & 0.74 & & \\
\hline \multicolumn{5}{|l|}{ Preoperative PSA level, ng/ml } \\
\hline (continuously, total range of risk) & $2.38(0.27-10.43)$ & 0.38 & - & - \\
\hline$>4$ vs. $\leq 4, \mathrm{ng} / \mathrm{ml}$ & $1.13(0.79-1.59)$ & 0.47 & & \\
\hline
\end{tabular}

$\mathrm{RR}=$ Relative risk.

studies have suggested that the presence of incidental $\mathrm{PC}$ at RC impacts on OS [17]. In this series, the rate of incidental PC was relatively high (43.7\%). In prior series, a high variation in the rates of incidental PC at RC ranging between 2 and $58 \%$ have been reported $[6,7,18$, 19].

In order to define the clinical significance of incidental PC, we used the Epstein criteria as outlined above [14]. These parameters have been consistently used in other series evaluating the clinical significance of incidental PC at RC [7]. In the present study, the rate of clinically significant PC was similar between centers (13-14\%). This suggests that the histopathologic evaluation of PC foci was conducted in the same way in the 3 participating centers over the study period of 15 years.

In order to better characterize each of the 3 groups, we conducted further analyses. We found that the presence and clinical significance of PC correlated with the performance of any prostate biopsy prior to RC, positive DRE, higher age at RC and higher preoperative PSA values. As in our centers the diagnostic work-up with PSA and DRE was usually done a few days prior to $\mathrm{RC}$, the treatment approach did not change for patients with suspicious findings. However, with regard to studies advocating prostate-sparing techniques to improve functional outcomes after RC $[7,20]$, our findings confirm the current clinical practice to use these parameters in order to rule out the presence of significant PC at RC.

In this study, mortality was significantly associated with age, advanced pathologic tumor and nodal stage, STSM, LVI and delivery of postoperative chemotherapy. These data underpin that the present cohort is comparable to similar larger series in terms of its primary tumor characteristics $[3,4]$.

We also found that node-negative patients with clinically significant PC were at higher risk for death compared to patients with insignificant or no PC. However, on multivariate analysis, only the classic pathological risk factors and age were associated with OS whereas clinically significant PC was not.

Nonetheless, an interesting, albeit surprising find of the present study was that LVI by BC cells as determined by immunohistochemistry was strongly associated with the presence of incidental PC. Of note, the rate of locally advanced BC and number of retrieved lymph nodes was not significantly different between the 3 groups. Thus, the question arises whether and how the presence of incidental PC might facilitate lymphovascular invasion of BC cells. This hypothetical question cannot to be adequately addressed based on the available retrospective data but deserves further basic research investigation. As recent data suggest an influence of the 
androgen pathway during the development and progression of muscle-invasive $\mathrm{BC}[9,10]$, this may represent a possible molecular link for the development of significant PC foci during progression of invasive BC cells.

This study has limitations inherent to its retrospective and multicenter nature. One limitation of this study is that our multicenter database did not contain data for recurrence-free and cancer-specific survival of all centers. Interestingly, we found that approximately $48 \%$ of significant PCs were palpable on DRE which may also be due to BC invasion as approximately $15 \%$ had pT4a BC. Conversely, the question arises whether transrectal biopsy in case of a positive DRE may be helpful in selecting patients who should be offered neoadjuvant treatment [1]. Despite the fact that the rate of clinically significant PC was very similar between centers, one cannot rule out an interobserver variability in the pathological assessment of RC specimens. Although we report on the number of retrieved lymph nodes as a surrogate marker for the meticulousness of pelvic LND, its association to the anatomical extent of LND is limited [21]. However, all patients were treated in academic centers by surgeons dedicated to the management of pa- tients with muscle-invasive BC. Nonetheless, owing to these limitations, the results of this study await external validation.

\section{Conclusions}

Although node-negative patients with clinically significant PC exhibited inferior OS in univariate analysis, this series did not find the clinical significance of incidental $\mathrm{PC}$ to be an independent predictor for OS after RC for BC. However, the positive correlation between incidental PC and LVI of $\mathrm{BC}$ deserves further investigation.

\section{Acknowledgments}

None.

\section{Disclosure Statement}

All authors declare no conflicts of interest related to the contents of this study. No funding was received for this study.

\section{References}

$>1$ Gakis G, Efstathiou J, Lerner SP, et al: ICUDEAU international consultation on bladder cancer 2012: radical cystectomy and bladder preservation for muscle-invasive urothelial carcinoma of the bladder. Eur Urol 2013;63: 45-57.

12 Witjes JA, Comperat E, Cowan NC, et al: EAU guidelines on muscle-invasive and metastatic bladder cancer: summary of the 2013 guidelines. Eur Urol 2014;65:778-792.

-3 Stein JP, Lieskovsky G, Cote R, et al: Radical cystectomy in the treatment of invasive bladder cancer: long-term results in $1,054 \mathrm{pa}$ tients. J Clin Oncol 2011;19:666-675.

4 Shariat SF, Karakiewicz PI, Palapattu GS, et al: Nomograms provide improved accuracy for predicting survival after radical cystectomy. Clin Cancer Res 2006;12:66636676.

5 Gakis G, Schilling D, Bedke J, et al: Incidental prostate cancer at radical cystoprostatectomy: implications for apex-sparing surgery. BJU Int 2010;105:468-471.

6 Gakis G, Stenzl A, Renninger M: Do we use the right criteria for determining the clinical significance of incidental prostate cancer at radical cystoprostatectomy? Scand J Urol 2013;47:358-362.

$>7$ Damiano R, Di Lorenzo G, Cantiello F, et al: Clinicopathologic features of prostate adenocarcinoma incidentally discovered at the time of radical cystectomy: an evidence-based analysis. Eur Urol 2007;52:648-657.

8 Bruins HM, Djaladat H, Ahmadi H, Sherrod A, Cai J, Miranda G, et al: Incidental prostate cancer in patients with bladder urothelial carcinoma: comprehensive analysis of 1,476 radical cystoprostatectomy specimens. J Urol 2013;190:1704-1709.

9 Gakis G, Stenzl A: Gender-specific differences in muscle-invasive bladder cancer: the concept of sex steroid sensitivity. World J Urol 2013;31:1059-1064.

10 Gakis G, Stenzl A, Renninger M: Evolution of the concept of androgen-sensitive bladder cancer. Scand J Urol 2013;47:173-178.

11 Sobin DH, Wittekind C: TNM Classification of Malignant Tumours. New York, WileyLiss, 2002.

12 Shim JW, Cho KS, Choi YD, et al: Diagnostic algorithm for papillary urothelial tumors in the urinary bladder. Virchows Arch 2008;452: 353-362.

13 McNeal JE, Redwine EA, Freiha FS, Stamey TA: Zonal distribution of prostatic adenocarcinoma. Correlation with histologic pattern and direction of spread. Am J Surg Pathol 1988;12:897-906.

14 Epstein JI, Walsh PC, Carmichael M, Brendler $\mathrm{CB}$ : Pathologic and clinical findings to predict tumor extent of nonpalpable (stage T1c) prostate cancer. JAMA 1994;271:368-374.
15 Brunocilla E, Pernetti R, Martorana G: The prognostic role of lymphovascular invasion in urothelial-cell carcinoma of upper and lower urinary tract. Anticancer Res 2011;31:35033506.

16 Rink M, Fajkovic H, Cha EK, et al: Death certificates are valid for the determination of cause of death in patients with upper and lower tract urothelial carcinoma. Eur Urol 2012; 61:854-855.

17 Sruogis A, Ulys A, Smailyte G, et al: Incidentally found prostate cancer and influence on overall survival after radical cystoprostatectomy. Prostate Cancer 2012;2012:690210.

18 Buse S, Höfner T, Müller SC, et al: Characterization and risk stratification of prostate cancer in patients undergoing radical cystoprostatectomy. Int J Urol 2013;20:866-871.

19 Pignot G, Salomon L, Neuzillet Y, et al: Clinicopathological characteristics of incidental prostate cancer discovered from radical cystoprostatectomy specimen: a multicenter French study. Ann Surg Oncol 2014;21:684-690.

20 Macek P, Sanchez-Salas R, Rozet F, et al: Prostate-sparing radical cystectomy for selected patients with bladder cancer. Urol Int 2013; 91:89-96.

21 Davies JD, Simons CM, Ruhotina N, et al: Anatomic basis for lymph node counts as measure of lymph node dissection extent: a cadaveric study. Urology 2013;81:358-363. 